\title{
Medical management after myocardial infarction
}

\author{
Wilbert S Aronow*,1 \\ ${ }^{1}$ Cardiology Division, Westchester Medical Center \& New York Medical College, Macy Pavilion, Room 141, Valhalla, NY 10595, \\ USA \\ *Author for correspondence: Tel.: +1 914493 5311; wsaronow@aol.com
}

"Control of coronary risk factors for secondary prevention is a cornerstone in post-MI patients to limit the progression of coronary heart disease"

First draft submitted: 23 March 2019; Accepted for publication: 28 March 2019; Published online: 31 May 2019

Keywords: angiotensin-converting enzyme inhibitors $\bullet$ antiplatelet drugs $\bullet \beta$ blockers $\bullet$ coronary risk factors $\bullet$ myocardial infarction $\bullet$ statins

It is well known that patients that have suffered from a myocardial infarction (MI) are at a significantly increased risk of another infarction in the future, making it imperative that appropriate secondary preventative measures are taken in the attempt to reduce this risk. This article aims to offer a brief summary of current recommendations for the medical management of patients' post-MI, based on the current available evidence.

\section{Management of major coronary risk factors}

Control of coronary risk factors for secondary prevention is a cornerstone in post-MI patients to limit the progression of coronary heart disease (CHD) and reduce cardiovascular events and mortality.

The American College of Cardiology (ACC)/American Heart Association (AHA) 2013 guidelines recommend that patients should be counseled on smoking cessation during and after hospitalization for MI [1]. A smoking cessation program should be recommended to smokers [1,2]. Patients should be advised at every physician office visit to avoid passive exposure to tobacco smoke at work, at home and in public places [2].

The patients with hypertension should have their blood pressure lowered to less than $130 / 80 \mathrm{mmHg}$ by lifestyle measures plus antihypertensive drugs [3]. The patients with hypertension after MI should be treated with a $\beta$ blocker plus an angiotensin-converting enzyme (ACE) inhibitor [3-5]. If a third antihypertensive drug is indicated, it should be a dihydropyridine calcium channel blocker (CCB), aldosterone antagonist or thiazide diuretic (preferably chlorthalidone) depending on the comorbidities [3-5]. If the left ventricular ejection fraction (LVEF) is reduced, the $\beta$ blocker used should be either carvedilol, metoprolol succinate or bisoprolol [3-5].

The patients with hypercholesterolemia after MI should be treated with lifestyle measures plus high-dose statins (40-80 mg of atorvastatin or $20-40 \mathrm{mg}$ of rosuvastatin) or maximum tolerated statin therapy [6]. The patients after MI with either a recent acute coronary syndrome or history of ischemic stroke, or symptomatic peripheral arterial disease or if they have multiple high-risk conditions (age 65 years and older, heterozygous familial hypercholesterolemia, history of prior coronary revascularization, diabetes mellitus, hypertension, chronic kidney disease, current smoking, history of heart failure) who have on maximally tolerated statin therapy a serum LDL-cholesterol of $\geq 70 \mathrm{mg} / \mathrm{dl}$, should have ezetimibe added to statin therapy [6]. If the LDL-cholesterol is still $\geq 70 \mathrm{mg} / \mathrm{dl}$ on maximally tolerated statin therapy plus ezetimibe, consider the addition of alirocumab or evolocumab to the therapeutic regimen [6].

Type 2 diabetes mellitus should be treated with lifestyle measures, an appropriate diet, weight reduction if indicated and exercise. Metformin is generally the initial drug to treat hyperglycemia [7]. A hemoglobin A1c target of $<7.0 \%$ is reasonable [2]. However, for elderly frail patients with multiple comorbidities, a target of $7.0-7.9 \%$ is recommended. 
Obesity should be treated with lifestyle modification. Guidelines from the AHA/ACC/Obesity Society recommend that patients with a BMI $\geq 35 \mathrm{~kg} / \mathrm{m}^{2}$ with an obesity-related comorbid condition who have not responded to lifestyle modification with or without pharmacotherapy to achieve sufficient weight loss should be referred to an experienced bariatric surgeon for consideration of bariatric surgery [8].

\section{General treatment recommendations post-MI}

The 2014 ACC/AHA guidelines recommend that patients after MI should be referred to a comprehensive cardiac rehabilitation program [9]. A symptom-limited exercise test is recommended before beginning an exercise program to know the safety of an exercise program and to guide the initial exercise program.

Aspirin $75-162 \mathrm{mg}$ daily is recommended in all patients with CHD unless contraindicated $[2,10]$. Clopidogrel $75 \mathrm{mg}$ daily is recommended as an alternative for patients who are intolerant of or allergic to aspirin $[2,10]$. The addition of a thienopyridine (clopidogrel $75 \mathrm{mg}$ daily, prasugrel $10 \mathrm{mg}$ daily or ticagrelor $90 \mathrm{mg}$ twice daily) in patients after an acute coronary syndrome, especially in those who have received a stent during percutaneous coronary intervention, causes a greater reduction in cardiovascular events than aspirin alone with an increased risk of bleeding [2,10]. Clopidogrel is generally used in elderly patients after MI. Prasugrel is not recommended for use in patients older than 75 years, for those with a prior stroke or transient ischemic attack or those with low body weight [9]. Proton pump inhibitors reduce the risk of gastrointestinal bleeding in patients being treated with dual antiplatelet therapy.

The AHA/ACC guidelines recommend as indications for long-term use of anticoagulants after MI: secondary prevention of MI in post-MI patients unable to tolerate daily aspirin or clopidogrel; in post-MI patients with atrial fibrillation; in post-MI patients with a LV thrombus, and; in post-MI patients with a mechanical heart valve [2]. Routine use of an anticoagulant with dual antiplatelet therapy is associated with an unacceptable bleeding risk, especially in elderly patients [11].

$\beta$ blockers are very effective antianginal and anti-ischemic agents that should be administered to all patients with angina pectoris or silent myocardial ischemia due to CHD unless there are specific contraindications to their use [12]. Teo et al. [13] analyzed 55 randomized controlled trials comprising 53,268 patients that investigated the use of $\beta$ blockers after MI. $\beta$ blockers significantly reduced all-cause mortality by $19 \%$ in this study [13]. A meta-analysis of trials also demonstrated that the use of $\beta$ blockers after non-Q-wave MI is likely to reduce all-cause mortality and recurrent MI by 25\% [14]. The AHA/ACC guidelines recommend that patients without a clear contraindication to $\beta$ blocker therapy should receive $\beta$ blockers within a few days of MI if not initiated acutely [2]. If the LVEF is reduced, carvedilol, metoprolol succinate or bisoprolol should be administered indefinitely. If the LVEF is normal, $\beta$ blockers should be used for at least 3 years. It is reasonable to continue $\beta$ blockers indefinitely in these patients [2]. $\beta$ blockers with intrinsic sympathomimetic activity should not be used.

Long-acting nitrates are effective antianginal and anti-ischemic drugs and should be administered alongside $\beta$ blockers following MI in patients that also have angina pectoris $[12,15]$. The prescribed dosage of oral isosorbide dinitrate should be gradually increased to a dose of $30-40 \mathrm{mg}$ three-times daily, if tolerated. A $60 \mathrm{mg}$ dose of isosorbide-5-mononitrate may be given once daily. There should be a nitrate-free interval of $12 \mathrm{~h}$ each day in order to avoid nitrate tolerance. During the nitrate-free interval, $\beta$ blockers should be used to prevent angina pectoris and rebound myocardial ischemia.

In the European trial on reduction of cardiac events with perindopril in stable coronary artery disease (EUROPA trial), at 4.2-year follow-up of 13,655 patients with prior MI and stable CHD compared with placebo, patients randomized to the ACE inhibitor perindopril had a 20\% significant reduction in cardiovascular death, recurrent MI or cardiac arrest [16]. The AHA/ACC guidelines recommend administration of an ACE inhibitor indefinitely after MI, especially if the LVEF is $\leq 40 \%$ and in patients who have hypertension, diabetes mellitus or chronic kidney disease, unless there are contraindications to their use [2]. It is reasonable to use an angiotensin receptor blocker after MI in patients who are ACE inhibitor tolerant [2].

At 16-month follow-up of 6632 patients after MI with a LVEF of $\leq 40 \%$ and either congestive heart failure or diabetes mellitus treated with an ACE inhibitor or angiotensin receptor blocker and $75 \%$ treated with $\beta$ blockers, compared with placebo treatment, patients randomized to the aldosterone antagonist eplerenone $50 \mathrm{mg}$ daily had a $15 \%$ significant reduction in all-cause mortality and a $13 \%$ significant reduction in cardiovascular death or hospitalization for cardiovascular events [17]. The AHA/ACC guidelines recommend use of an aldosterone antagonist after MI in patients receiving therapeutic doses of an ACE inhibitor plus a $\beta$ blocker who have a LVEF of $\leq 40 \%$ and either diabetes mellitus or heart failure without significant renal dysfunction or hyperkalemia [2]. 
A CCB should not be used after MI unless it is indicated for the treatment of hypertension in patients already receiving a $\beta$ blocker plus an ACE inhibitor or in patients with persistent angina pectoris despite treatment with a $\beta$ blocker plus a long-acting nitrate [12]. A nondihydropyridine CCB such as verapamil or diltiazem should be added to the therapeutic regimen if the LVEF is normal. If the LVEF is abnormal, a dihydropyridine CCB such as amlodipine or felodipine should be added to the therapeutic regimen.

At 6.8-year follow-up of 2763 women with documented CHD in the Heart Estrogen/Progestin Replacement Study (HERS), compared with placebo, hormone replacement did not reduce cardiovascular events and insignificantly increased all-cause mortality by $10 \%$ [18]. Hormone replacement therapy significantly increased venous thromboembolism by $208 \%$ and biliary tract surgery by $48 \%$. Hormone replacement therapy also insignificantly increased the incidence of any cancer by $19 \%$ and of any fracture by $4 \%$. The investigators concluded that hormone replacement therapy should not be used to reduce cardiovascular events in women with CHD [18]. On the basis of the available data, current AHA/ACC guidelines give the following class III recommendation (harmful, should not be performed) for the secondary prevention of coronary events in postmenopausal women after MI [9].

A meta-analysis of 59 randomized controlled trials comprising 23,229 patients that investigated the use of class I antiarrhythmic drugs after MI showed that these drugs significantly increased mortality by $14 \%[13]$. $\beta$ blockers are the only antiarrhythmic drugs that have been demonstrated to reduce mortality in patients with nonsustained ventricular tachycardia or complex ventricular arrhythmias after MI in patients with abnormal [19] or normal LVEF [20]. The ACC/AHA/Heart Rhythm Society guidelines recommend implantation of an automatic implantable cardioverter-defibrillator to reduce all-cause mortality in New York Heart Association class II or III patients with a LVEF $<35 \%$ due to a prior MI at least 40 days previously and in New York Heart Association class I patients with a LVEF $<30 \%$ due to a prior MI at least 40 days previously [21].

Evidence from cohort studies and a randomized clinical trial indicate that annual vaccination against seasonal influenza reduces cardiovascular events and mortality in patients with cardiovascular disease [22]. The AHA/ACC guidelines recommend an annual influenza vaccination in the patients with CHD [2,22].

Financial \& competing interests disclosure

The author has no relevant affiliations or financial involvement with any organization or entity with a financial interest in or financial conflict with the subject matter or materials discussed in the manuscript. This includes employment, consultancies, honoraria, stock ownership or options, expert testimony, grants or patents received or pending, or royalties.

No writing assistance was utilized in the production of this manuscript.

\section{References}

1. O'Gara PT, Kushner FG, Ascheim FG et al. 2013 ACCF/AHA guidelines for the management of ST-elevation myocardial infarction. A report of the American College of Cardiology Foundation/American Heart Association Task Force on Practice Guidelines. J. Am. Coll. Cardiol. 61(4), e78-e140 (2013).

2. Smith SC Jr, Benjamin EJ, Bonow RO et al. AHA/ACCF secondary prevention and risk reduction therapy for patients with coronary and other atherosclerotic vascular disease: 2011 update. A guideline from the American Heart Association and American College of Cardiology Foundation. Endorsed by the World Heart Federation and the Preventive Cardiovascular Nurses Association. J. Am. Coll. Cardiol. 58(23), 2432-2446 (2011).

3. Whelton PK, Carey RM, Aronow WS et al. 2017 ACC/AHA/AAPA/ABC/ACPM/ AGS/APhA/ASH/ASPC/NMA/ PCNA guideline for the prevention, detection, evaluation and management of high blood pressure in adults. A report of the American College of Cardiology/American Heart Association Task Force on Clinical Practice Guidelines. J. Am. Coll. Cardiol. 71(6), e127-e248 (2018).

4. Aronow WS, Fleg JL, Pepine CJ et al. ACCF/AHA 2011 expert consensus document on hypertension in the elderly: a report of the American College of Cardiology Foundation Task Force on Clinical Expert Consensus Documents. J. Am. Coll. Cardiol. 57(20), 2037-2114 (2011).

5. Rosendorff C, Lackland DT, Allison M, Aronow WS et al. AHA/ACC/ASH scientific statement. Treatment of hypertension in patients with coronary artery disease. J. Am. Coll. Cardiol. 65(18), 1998-2038 (2015).

6. Grundy SM, Stone NJ, Bailey AL et al. 2018 AHA/ACC/AACVPR/AAPA/ ABC/ACPM/ADA/AGS/APhA/ASPC/NLA/PCNA guideline on the management of blood cholesterol. Circulation doi:0.1161/CIR.0000000000000625 (2018) (Epub ahead of print).

7. Quaseem A, Humphrey LL, Sweet DE, Starkey M, Shekelle P, Clinical Guidelines Committee of the American College of Physicians. Oral pharmacological treatment of Type 2 diabetes mellitus. A clinical practice guideline from the American College of Physicians. Ann. Intern. Med. 156(3), 218-231 (2012). 
8. Jensen MD, Ryan DH, Apovian CM et al. 2013 AHA/ACC/TOS guideline for the management of overweight and obesity in adults: A report of the American College of Cardiology/American Heart Association Task Force on Practice Guidelines and the Obesity Society. Circulation 129(25 Suppl. 2), S102-S138 (2018).

9. Amsterdam EA, Wenger NK, Brindis RG et al. 2014 AHA/ACC guideline for the management of patients with non-ST-elevation acute coronary syndromes. A report of the American Cardiology/American Heart Association Task Force on Practice Guidelines. J. Am. Coll. Cardiol. 64(24), e139-e228 (2014).

10. Fleg JL, Aronow WS, Frishman WH. Cardiovascular drug therapy in the elderly. Benefits and challenges. Nat. Rev. Cardiol. 8(1), 13-28 (2011).

11. Lamberts M, Olesen JB, Ruwald MH et al. Bleeding after initiation of multiple antithrombotic drugs, including triple therapy, in atrial fibrillation patients following myocardial infarction and coronary intervention: a nationwide cohort study. Circulation 126(10), 1185-1193 (2012).

12. Aronow WS, Frishman WH. Angina pectoris in the elderly. In: Tresch and Aronow's Cardiovascular Disease in the Elderly: (6th Edition). Aronow WS, Fleg J, Rich MW (Eds). CRC Press, FL, USA, 187-205 (2019).

13. Teo KK, Yusuf S, Furberg CD. Effects of prophylactic antiarrhythmic drug therapy in acute myocardial infarction. An overview of results from randomized controlled trials. JAMA 270(13), 1589-1595 (1993).

14. Yusuf S, Wittes J, Probstfield J. Evaluating effects of treatment within a clinical trial: the case of non-Q-wave myocardial infarction and beta blockers. Am. J. Cardiol. 66(2), 220-222 (1990).

15. Danahy DT, Aronow WS. Hemodynamics and antianginal effects of high-dose oral isosorbide dinitrate after chronic use. Circulation 56(2), 205-212 (1977).

16. The EURopean trial On reduction of cardiac events with Perindopril in stable coronary Artery disease Investigators. Efficacy of perindopril in reduction of cardiovascular events among patients with stable coronary artery disease: randomized, double-blind, placebo-controlled multicentre trial (the EUROPA study). Lancet 362(9386), 782-788 (2003).

17. Pitt B, Remme W, Zannad F et al. Eplerenone: a selective aldosrerone blocker in patients with left ventricular dysfunction after myocardial infarction. N. Engl. J. Med. 348(14), 1309-1321 (2003).

18. Grady D, Herrington D, Bittner V et al. Cardiovascular disease outcomes during 6.8 years of hormone therapy. Heart and Estrogen/Progestin Replacement Study Follow-up (HERS II). JAMA 288(1), 58-66 (2002).

19. Kennedy HL, Brooks MM, Barker AH et al. Beta-blocker therapy in the Cardiac Arrhythmia Suppression Trial. Am. J. Cardiol. 74(7), 674-680 (1994).

20. Aronow WS, Ahn C, Mercando AD et al. Effect of propranolol versus no antiarrhythmic drug on sudden cardiac death, total cardiac death, and total death in patients $\geq 62$ years of age with heart disease, complex ventricular arrhythmias, and left ventricular ejection fraction $\geq 40 \%$. Am. J. Cardiol. 74(3), 267-270 (1994).

21. Epstein AE, DiMarco JP, Ellenbogen KA et al. ACC/AHA/HRS guidelines for device-based therapy of cardiac rhythm abnormalities. A report of the American College of Cardiology/American Heart Association Task Force on Practice Guidelines (Writing Committee to Revise the ACC/AHA/NASPE 2002 Guideline Update for Implantation of Cardiac Pacemakers and Antiarrhythmic Devices. Developed in collaboration with the American Association for Thoracic Surgery and Society of Thoracic Surgeons). J. Am. Coll. Cardiol. 51(21), e1-e62 (2008).

22. Davis MM, Taubert $\mathrm{K}$, Benin AL et al. Influenza as secondary prevention for cardiovascular disease: a science advisory from the American Heart Association/American College of Cardiology. J. Am. Coll. Cardiol. 48(7), 1498-1502 (2006). 